\title{
PERCEPÇÃO AMBIENTAL DOS ESTUDANTES DO CURSO TÉCNICO EM ALIMENTOS DO PROEJA NO IFRN - CAMPUS CURRAIS NOVOS
}

\author{
Luciana de Castro Medeiros \\ Servidora do IFRN, Campus Currais Novos, especialista em PROEJA (IFRN), licenciada e \\ bacharel em Ciências Biológicas (UFRN), técnica em Meio Ambiente (CEFET/RN) \\ luciana.castro@ifrn.edu.br \\ Wyllys Abel Farkatt Tabosa \\ Professor do IFRN, Campus Central-Natal, licenciado em Ciências Biológicas (UFRN), \\ mestre em Desenvolvimento e Meio Ambiente (UFPB) e doutor em Educação (UFRN) \\ wyllys.farkatt@ifrn.edu.br
}

\begin{abstract}
RESUMO
O PROEJA, instituído no âmbito federal através do Decreto $N^{\circ} 5.840 / 2006$, reflete uma necessidade de atender as demandas sociais, apresentando como proposta formar jovens e adultos que estavam fora do sistema escolar para serem cidadãos profissionais, de modo a produzir conhecimentos e compreender sua realidade. No IFRN - Campus Currais Novos é oferecido o curso técnico em Alimentos na modalidade EJA, no qual se espera deste profissional a compreensão ambiental, principalmente, nas empresas de alimentos. Este estudo pretende avaliar a percepção ambiental dos estudantes que estão cursando o $4^{\circ}$ período do curso técnico de nível médio integrado em Alimentos na modalidade de educação de jovens e adultos ofertado no IFRN - Campus Currais Novos. Foram aplicados questionários, contendo questões objetivas envolvendo temas sobre a sustentabilidade ambiental voltado às práticas da vida cotidiana e nas empresas de alimentos. Os dados obtidos mostraram que os alunos do PROEJA possuem um repertório de representações conhecimentos adquiridos pela vivência, pela cultura e senso comum, acerca das questões ambientais, porém expressam enormes possibilidades de mudanças comportamentais que foram apontados na pesquisa.
\end{abstract}

PALAVRAS-CHAVE: PROEJA, percepção ambiental, educação ambiental

\section{ENVIRONMENTAL AWARENESS OF STUDENTS IN TECHNICAL COURSE OF FOOD IN PROEJA IFRN - CAMPUS CURRAIS NOVOS}

\begin{abstract}
The PROEJA established under federal through Decree No. 5.840/2006, reflects a need to meet social demands, presenting as proposed train young people and adults who were outside the school system not only to the world of work, but also to be citizens professionals in order to produce knowledge and understand their reality. In IFRN Campus Currais Novos technical course is offered in Food modality EJA, which are expected to understand this professional environment, especially in food companies. This study aims to evaluate the environmental awareness of students who are attending the 4th period of the current technical level integrated in Food in the mode of educating youth and adults offered in IFRN - Campus Currais Novos. The methodology adopted was the use of questionnaires, containing questions on topics involving environmental sustainability back to the practices of daily life and food companies. The data showed that students of
\end{abstract}


PROEJA have a repertoire representations of knowledge acquired by experience, culture and common sense about environmental issues, but expressed great possibilities of behavioral changes that were mentioned in the survey.

KEY-WORDS: PROEJA, environmental awareness, environmental education 


\section{PERCEPÇÃO AMBIENTAL DOS ESTUDANTES DO CURSO TÉCNICO EM ALIMENTOS DO PROEJA NO IFRN - CAMPUS CURRAIS NOVOS}

\section{INTRODUÇÃO}

O Campus Currais Novos do IFRN está situado na região do Seridó Potiguar na cidade de Currais Novos, fruto da $1^{a}$ fase do Plano de Expansão da Rede Federal de Educação Profissional e Tecnológica implantado pelo governo federal, foi inaugurado no ano de 2006. Neste mesmo ano iniciou a oferta de vagas para turmas do curso técnico de nível médio integrado em Alimentos na modalidade de EJA.

A instituição espera que o estudante do curso técnico de nível médio integrado em Alimentos na modalidade EJA seja apto a atuar em diversas áreas nas empresas de alimentos, apresentando também uma formação voltada para as questões ambientais, sendo capazes de acompanhar e monitorar os aspectos ambientais e aplicar as normas de desenvolvimento sustentável junto às empresas de alimentos.

Vale ressaltar que a função social do Instituto Federal de Educação, Ciência e Tecnologia do Rio Grande do Norte é a formação de profissionais-cidadãos, com consciência políticaeconômica-social e ambiental.

Nos últimos anos a preocupação com a questão ambiental vem sendo crescente, colocando, portanto, em evidência a educação ambiental nas escolas, através do emprego de temas ambientais como veículos de aprendizagem e de conscientização a fim de que os atores sociais alcancem a percepção dos problemas ambientais da sociedade moderna (BARROS; SILVA, 2009).

A educação tem passado por mudanças significativas, tendo seu papel social, ambiental e cultural sempre crescente e em sintonia com uma sociedade em transformação, com novas demandas e temáticas sociais (SILVA; LIMA; TAVARES, 2007). Realmente a educação é, segundo Carvalho (2001, p. 189), "um campo altamente sensível as novas demandas e temáticas sociais", na qual insere a preocupação ambiental em seu universo educativo.

Uma dessas demandas sociais que refletem um novo formato de política educacional do governo brasileiro é o Programa Nacional de Integração da Educação Profissional com a Educação Básica na Modalidade de Educação de Jovens e Adultos - PROEJA, que tem como proposta formar jovens e adultos que estão fora do sistema escolar pela própria deficiência do alcance social da educação brasileira não apenas para o mundo do trabalho, mas também para se tornarem cidadãos capacitados para a atividade laboral, de modo a produzir conhecimentos e fazer avançar a compreensão da realidade social, cultural e ambiental (BRASIL, 2007).

O PROEJA foi instituído no âmbito da Rede Federal de Educação Profissional e Tecnológica através do Decreto de $\mathrm{n}^{\circ}$ 5.840/2006. Desde então o Instituto Federal de Educação, Ciência e Tecnologia do Rio Grande do Norte - IFRN oferece cursos técnicos dentro do Programa de Integração da Educação Profissional ao Ensino Médio na Modalidade de Educação de Jovens e Adultos - PROEJA (HENRIQUE; OLIVEIRA, 2007). 
Nessa perspectiva, este estudo pretende avaliar a percepção ambiental dos estudantes matriculados no $4^{\circ}$ período do curso técnico de nível médio integrado em Alimentos na modalidade de educação de jovens e adultos ofertado no IFRN - Campus Currais Novos, a fim de analisar a formação deles como profissionais-cidadãos comprometidos com o meio ambiente.

Avaliar a percepção dos indivíduos é uma tarefa complexa, pois cada indivíduo tem um olhar, uma interpretação e uma resposta diferente frente às questões ambientais, assim, o estudo da percepção ambiental se faz necessário para que se possa compreender a relação entre homem e meio ambiente e suas implicações na sociedade (SANTOS; MORAIS, 2009; CALDAS; RODRIGUES, 2009)

\section{FUNDAMENTAÇÃO TEÓRICA}

Nesta pesquisa, a percepção ambiental é entendida como a tendência geral pelas quais as pessoas desenvolvem atitudes e sentimentos pelo ambiente (ALTMAN; CHEMERS, 1989 apud BERGMANN; PEDROZO, 2007).

Percepção esta que serve de instrumento para a educação ambiental tratada no âmbito escolar, de modo que ao se tomar conhecimento da percepção ambiental de estudantes temse a oportunidade de compreender a relação homem-natureza entendida neste processo educativo dentro da Instituição de ensino. Do mesmo modo, em programas de educação ambiental o sucesso é alcançado quando os participantes atingem o nível de percepção ambiental esperado (REIS; MORAIS, 2009).

$\mathrm{Na}$ atualidade, a maior preocupação com a discussão da Educação Ambiental nas escolas é a construção de referências conceituais, estratégias e propostas metodológicas que permitam a compreensão dos alunos da realidade atual dos problemas sócio-ambientais e a obtenção de soluções palpáveis para tais problemas (QUEIROZ, 2002).

A educação ambiental é mencionada no atual Plano Nacional de Educação (PNE), de modo que ela deva ser implementada no ensino fundamental e médio de acordo com os preceitos da Política Nacional de Educação Ambiental. Já os Parâmetros Curriculares Nacionais $(\mathrm{PCN})$, considerado o referencial orientador para o programa pedagógico das escolas, abordam a operacionalização da educação ambiental em sala de aula de maneira interdisciplinar (LIPAI; LAYRARGUES; PEDRO, 2007).

A visão que se tem sobre a Educação Ambiental não pode ser baseada apenas como meio de abordar as questões ambientais, mas a EA deve proporcionar aos indivíduos a percepção da natureza de modo complexo, compreendo as interações entre aspectos físicos, socioculturais e político-econômicos que compõem a relação homem/meio (CANDIANI et al, 2004), transformando os homens em cidadãos comprometidos com as questões ambientais e levando-os a conscientização da utilização dos recursos naturais.

Neste trabalho o termo "Educação Ambiental" é tratado como meio para formação de cidadãos, conscientes de seus deveres e direitos, com um olhar diferenciado para a relação do homem com a natureza, tendo seus comportamentos e percepções condizentes com a formação de profissionais-cidadãos a que o IFRN se compromete diante do curso técnico em Alimentos na modalidade EJA e não apenas como disciplina ou conteúdo de alguma disciplina. 
Pesquisar sobre a percepção ambiental dos indivíduos é importante para se identificar a verdadeira relação existente entre o homem e a natureza - ou homem e meio ambiente. A partir desta identificação é possível planejar e implementar programas de Educação ambiental dentro e fora da escola.

Miranda (2007) afirma que a aprendizagem ambiental faz parte de um saber pedagógico, analítico e interpretativo utilizando-se do conhecimento comum, empírico sobre a sustentabilidade ecológica, social, cultural e econômica do planeta. É, portanto, um conhecimento prático que requer estratégias e ações de ensino-aprendizagem dentro e fora da escola, sendo mediado por um educador que relacione a realidade que vivemos aos das teorias, buscando que os sujeitos alçassem um olhar crítico sobre a realidade ambiental local, regional e mundial.

Para Freire (1987, p. 106) "no momento em que a percepção crítica se instaura, na mesma ação, se desenvolve um clima de esperança e confiança que leva os homens a empenha-se na superação dos problemas". Este pensador expõe que se o homem tem uma "percepção parcializada da realidade" não tem a possibilidade de uma ação autêntica sobre esta realidade.

Desta forma pode-se considerar que para se alcançar o objetivo de transformar a forma de olhar, ou perceber, o ambiente deve-se implantar um programa de educação ambiental voltado para a realidade da sociedade e maneira prática e não apenas teórica, objetivando mudanças de comportamentos e atitudes ambientalmente corretas a fim de os indivíduos atingirem o pensamento critico e reflexivo sobre tais ações.

\section{METODOLOGIA}

$\mathrm{Na}$ metodologia optou-se como instrumento da pesquisa a aplicação de questionários com o objetivo de avaliar a percepção ambiental dos estudantes do curso técnico de nível médio integrado em Alimentos na modalidade EJA, considerando a relação entre o mundo real e o sujeito - pesquisa qualitativa - e pela expressão de porcentagem dos dados - pesquisa quantitativa (SILVA; MENEZES, 2001). O questionário é considerado um instrumento de coleta de dados que busca informações a respeito de crenças, comportamentos, sentimentos, expectativas, avaliação, situações vivenciadas, entre outros dados de interesse do pesquisador e requer certa dose de sensibilidade e motivação para conquistar o público em estudo a respondê-lo (OLIVEIRA, 2007 apud LIRA; RICARTE, 2009).

A aplicação dos questionários da pesquisa de campo foi realizada com os alunos do $4^{\circ}$ período do curso técnico integrado em Alimentos na modalidade EJA em sala de aula no turno noturno. Estão matriculados na referida turma o total de 23 estudantes, porém a amostragem foi de 20 questionários, ou seja, 87\% da turma, no dia da realização da pesquisa houve dois alunos faltosos e um aluno que se recusou a participar da pesquisa alegando não saber responder às questões.

Os questionários continham 12 questões objetivas envolvendo temas sobre a sustentabilidade ambiental voltado às práticas da vida cotidiana e nas empresas de alimentos. Os temas abordados nos questionários envolveram os resíduos sólidos (3), poluição e desperdício da água (2), impactos ambientais de empresas alimentícias (6) e sobre a visão que eles têm da formação de técnico em alimentos acerca dos aspectos ambientais nas empresas (1). 
A primeira parte do questionário foi realizada uma breve caracterização do entrevistado a fim de conhecer o gênero e a faixa etária predominante da turma objeto da pesquisa.

\section{RESULTADOS E DISCUSSÃO}

Dos 20 alunos que responderam ao questionário, $80 \%$ são do sexo feminino e $20 \%$ do sexo masculino.

Este dado apresenta uma diferença significativa em relação ao estudo de Henrique e Oliveira (2007), no qual caracterizaram uma turma do Curso Técnico de Nível Médio Integrado em Controle Ambiental na Modalidade de Educação de Jovens e Adultos e os resultados mostraram que a maioria dos alunos $(78 \%)$ era do sexo masculino. Os autores refletiram que este dado aponta que as mulheres ficam impossibilitadas de aproveitar as oportunidades de crescimento intelectual e profissional devidos aos encargos familiares e domésticos.

Em contrapartida, os estudos realizados por Lira e Ricarte (2009) na então Unidade Descentralizada de Currais Novos com estudantes do Curso Técnico em Alimentos Integrado na modalidade de Jovens e Adultos que ingressaram na instituição no semestre letivo de 2006/2, apontou que a representação feminina entre os alunos foi de $66 \%$, enquanto $34 \%$ eram do sexo masculino, sendo equivalente aos resultados encontrados na presente pesquisa.

Em relação à faixa etária 14 alunos (70\%) estão na faixa dos 21 aos 50 anos sendo, portanto, considerados adultos, e 6 (30\%) fazem parte da faixa dos 18 aos 21 anos, considerados jovens, porém nenhum se enquadrou na faixa etária com mais de 50 anos, considerados idosos (Gráfico 1).

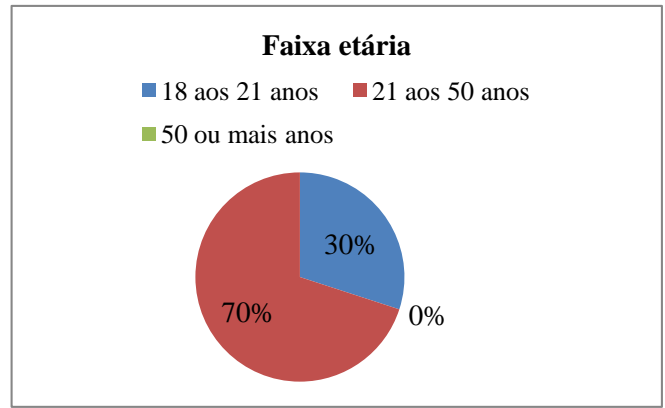

\section{Gráfico 1 - Faixa etária dos alunos objeto da pesquisa}

Deste modo vê-se que a turma em questão é composta, em sua maioria, por alunos adultos. Resultado este que também diferencia do encontrado por Henrique e Oliveira (2007), que obtiveram 50\% dos alunos situados na faixa etária entre 17 e 20 anos, e por Lira e Ricarte (2009), que apontam 55\% dos estudantes apresentavam idade inserida na faixa de 17 a 25 anos. Os resultados desses autores mostram uma característica bastante encontrada em turmas de EJA em escolas do Brasil, que é a presença considerável de jovens. Este fenômeno não está presente na turma aqui analisada. 
Na primeira questão sobre o tema sustentabilidade ambiental, os estudantes responderam se realizavam coleta seletiva em suas residências ou no trabalho. Obteve-se o resultado que $50 \%$ deles não realizavam e $50 \%$ realizavam (Gráfico 2).

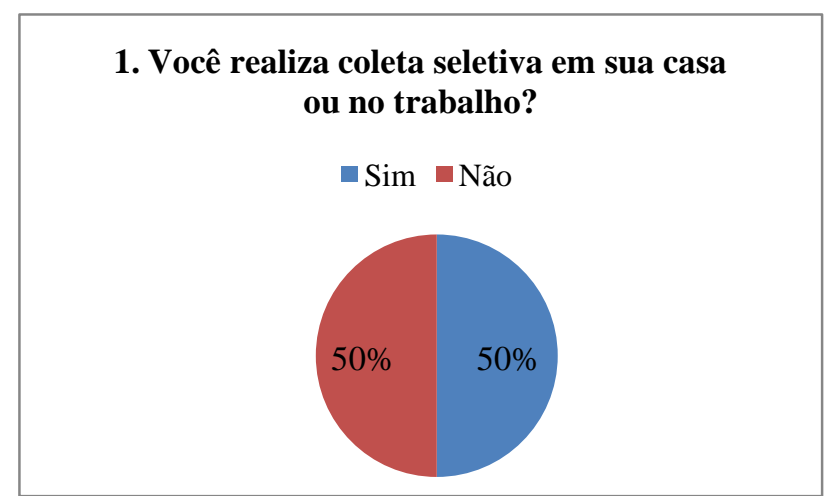

\section{Gráfico 2 - Porcentagem dos alunos que realizam coleta seletiva em suas residências ou em seu trabalho.}

Este resultado diferencia do encontrado por Medeiros (2009), que ao analisar a consciência ambiental dos estudantes concluintes do PROEJA no IFRN - Campus Currais Novos obteve que $86,67 \%$ dos alunos concluintes do PROEJA Alimentos não fazem coleta seletiva em suas casas. O que nos mostra uma diferenciação dos alunos concluintes dos alunos que estão cursando o mesmo curso.

Na segunda questão abordou-se o destino dos resíduos sólidos gerados nas residências dos alunos. Os resultados mostraram que $60 \%$ deles afirmam que são destinados para um lixão, $30 \%$ para um aterro e $10 \%$ afirmaram que não sabiam o destino do lixo produzido em sua casa, como demonstra o gráfico abaixo.

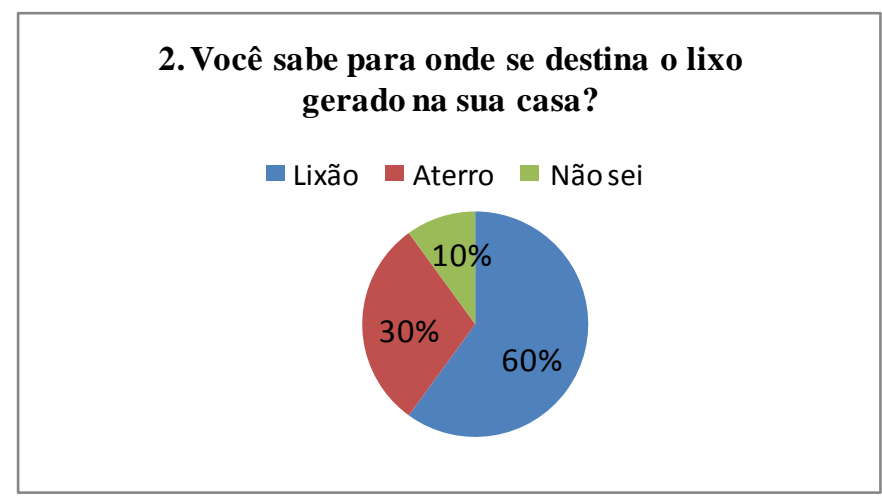

\section{Gráfico 3 - Porcentagem dos alunos que afirmam para onde se destinam os resíduos sólidos gerados seus suas residências.}

É importante levar em consideração que os 23 alunos da turma em questão residem no município de Currais Novos. Vale ressaltar ainda que a prefeitura de Currais Novos dispõe de um aterro controlado que se encontra em processo de licenciamento junto ao Instituto de Desenvolvimento Sustentável e Meio Ambiente do Rio Grande do Norte - IDEMA. Podese também frisar que, mesmo sendo uma porcentagem baixa, mas é preocupante alunos com formação para percepção ambiental dentro das empresas de alimentos não se interessarem em saber o destino dos resíduos sólidos produzidos em suas casas. 
Na terceira questão sobre resíduos sólidos, $70 \%$ afirmaram que às vezes costumam jogar lixo nas vias públicas, principalmente quando não há lixeiro por perto e apenas $30 \%$ afirmam que nunca jogam lixo nas vias públicas (Gráfico 4).

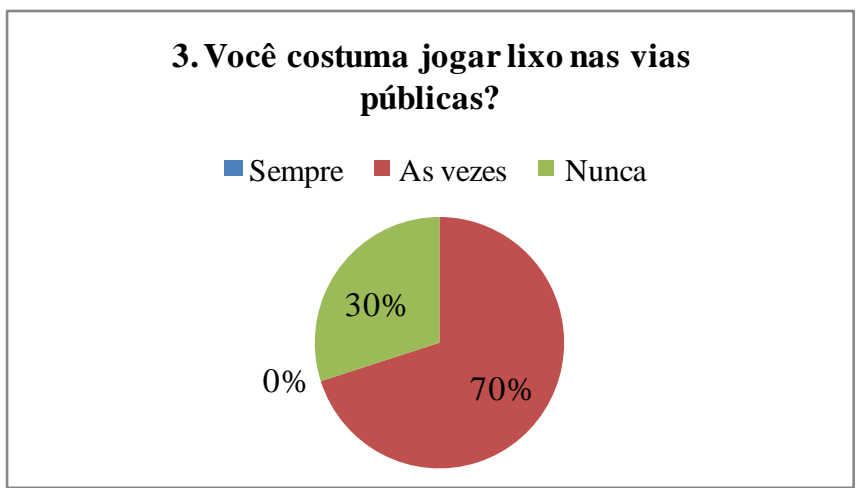

Gráfico 4 - Porcentagem dos alunos que lançam resíduos sólidos em vias públicas.

Este resultado difere do encontrado do estudo de Medeiros (2009), que apontou que 20\% dos alunos concluintes do PROEJA alimentos costumam jogar lixo nas vias públicas. A autora considerou a ação preocupante mesmo a minoria afirmando realizar esta prática. No presente estudo os resultados se mostram ainda mais preocupantes já que a maioria dos alunos tem o hábito de lançar os resíduos em vias públicas sem a menor preocupação com a cidadania, que também leva em consideração os deveres do indivíduo com a sociedade e com o coletivo, no qual há direitos e deveres a serem cumpridos.

A quarta e quinta questão é sobre o recurso natural finito mais importante aos seres vivos, a água. Primeiro os estudantes foram questionados se havia em sua cidade algum corpo d'água poluído. O gráfico abaixo ilustra que $20 \%$ dos alunos responderam que não havia rio, lago, lagoa ou açude poluído em sua cidade, porém $80 \%$ responderam que havia e foi pedido que eles dissessem quais os corpos d'água que eles consideram poluídos e ainda, a maioria desses $(43,75 \%)$ afirmou que o Açude Público do Totoró de Baixo, ou Açude do Governo, é o mais poluído, 37,5\% consideram o Açude Durval poluído, 6,25\% citou o Rio Totoró, $6,25 \%$ não citou nenhum corpo d'água e os outros $6,25 \%$ definiu quase todos os já citados. Esses corpos d'água estão inseridos na área urbana e rural do município de Currais Novos e são alvos da constante poluição causada pela ação antrópica nas suas margens. 


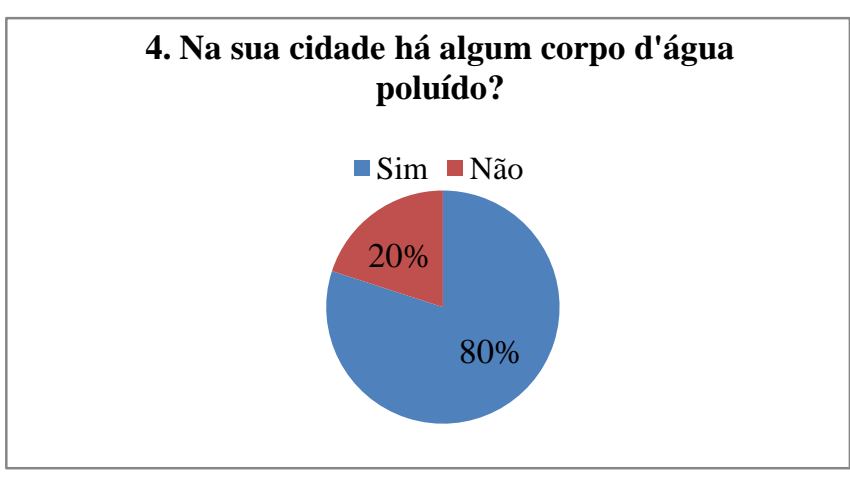

4.1. Quais?

- Açude do Governo açude Durval

घio Totoró $\quad$ Não definiu

n Definiu vários

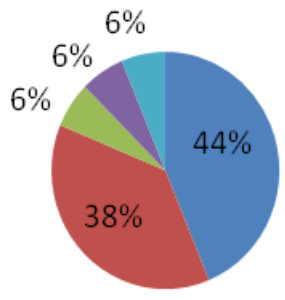

\section{Gráfico 5 - Porcentagens dos alunos que afirmaram que existem corpos d'água} considerados poluídos, e quais eles listaram.

A quinta questão foi sobre a importância da diminuição do consumo exagerado de água nas empresas. 95\% dos estudantes afirmaram que acham importante diminuir o consumo de água nas empresas, desses $89,47 \%$ apontam que o motivo desta preocupação seria para evitar a escassez de água e diminuir a geração de efluentes lançados no meio ambiente, $5,88 \%$ dos alunos afirmam que o motivo é para a conta de água ser menor e a empresa ter mais lucro e 5,88\% apontam os dois motivos como sendo importantes para a preocupação com a diminuição do consumo de água (Gráfico 6).

Este resultado apresenta-se semelhante ao apresentado por Medeiros (2009) que mostrou em sua pesquisa que $80 \%$ dos alunos disseram que economizam água em casa e/ou no Campus que estudavam, porém no estudo desta autora apenas $16,67 \%$ economizam água pelo motivo ambiental e $83,33 \%$ pelo motivo econômico. 


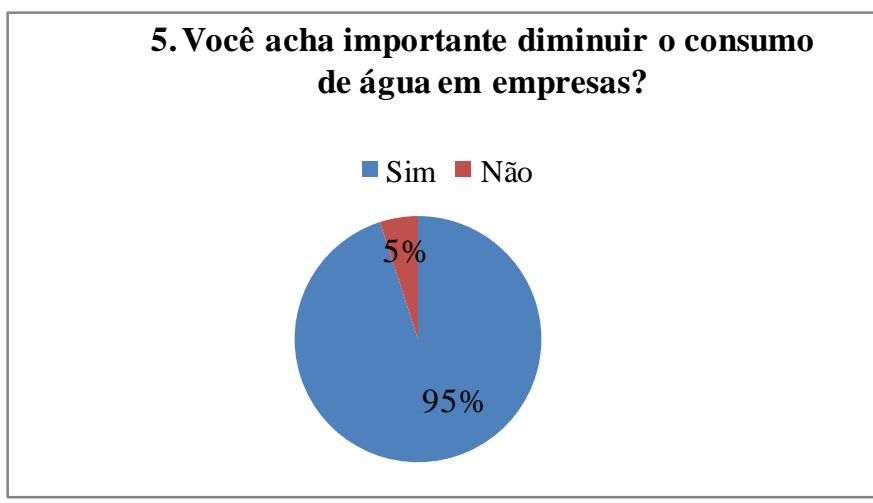

\subsection{Por qual motivo?}

- A conta de água será menor e a empresa lucrará mais

- Evita a escassez de água e diminui os efluentes gerados

Ambos

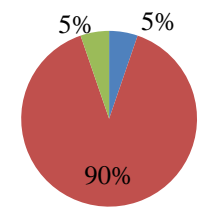

\section{Gráfico 6 - Porcentagens dos alunos que acreditam ser importante diminuir o consumo de água nas empresas e quais os motivos desta preocupação.}

A sexta questão foi perguntada de forma objetiva "sim" ou "não" se quando eles compram um produto alimentício tem a preocupação em verificar se a empresa fabricante tem responsabilidade com o meio ambiente. 55\% responderam que não tem esta preocupação ao comprar produtos alimentícios, e $45 \%$ responderam que possuem esta preocupação (Gráfico 7).

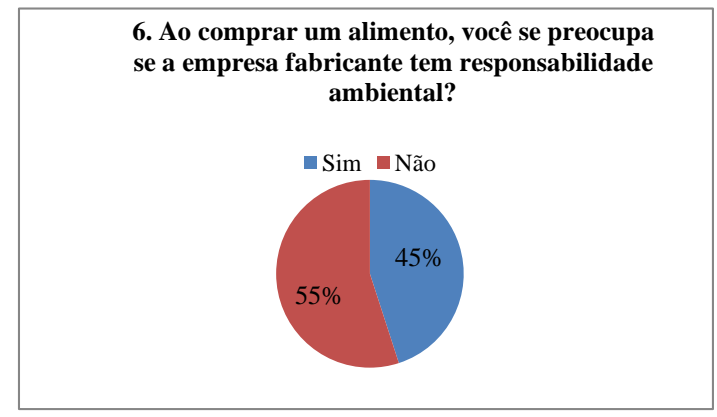

Gráfico 7 - Porcentagens dos alunos que acreditam ser importante diminuir o consumo de água nas empresas e quais os motivos desta preocupação.

Reis e Morais (2009) obtiveram resultados mais satisfatórios quando realizaram este questionamento com alunos do último módulo do curso de Edificações na modalidade de ensino de Jovens e Adultos do Instituto Federal de Educação, Ciência e Tecnologia do 
Piauí, de modo que $70 \%$ dos alunos ao comprar algum produto sempre verificam se o fabricante pratica ações ambientais.

Na sétima questão, sobre a sustentabilidade ambiental em empresas de alimentos, $100 \%$ dos alunos implementariam medidas de redução de desperdícios de produtos e de matériaprima caso fossem gerente ou proprietário de uma empresa de alimentos. Quando questionado o motivo desta preocupação, 55\% disseram que é para evitar o aumento da geração de resíduos sólidos, apontando uma preocupação com o meio ambiente, $35 \%$ afirmaram que era para evitar o aumento de gastos desnecessários, colocando o interesse econômico como motivação da redução de desperdícios e $10 \%$ afirmaram que ambas alternativas os motivariam a esta preocupação, como ilustrado no gráfico em seguida.
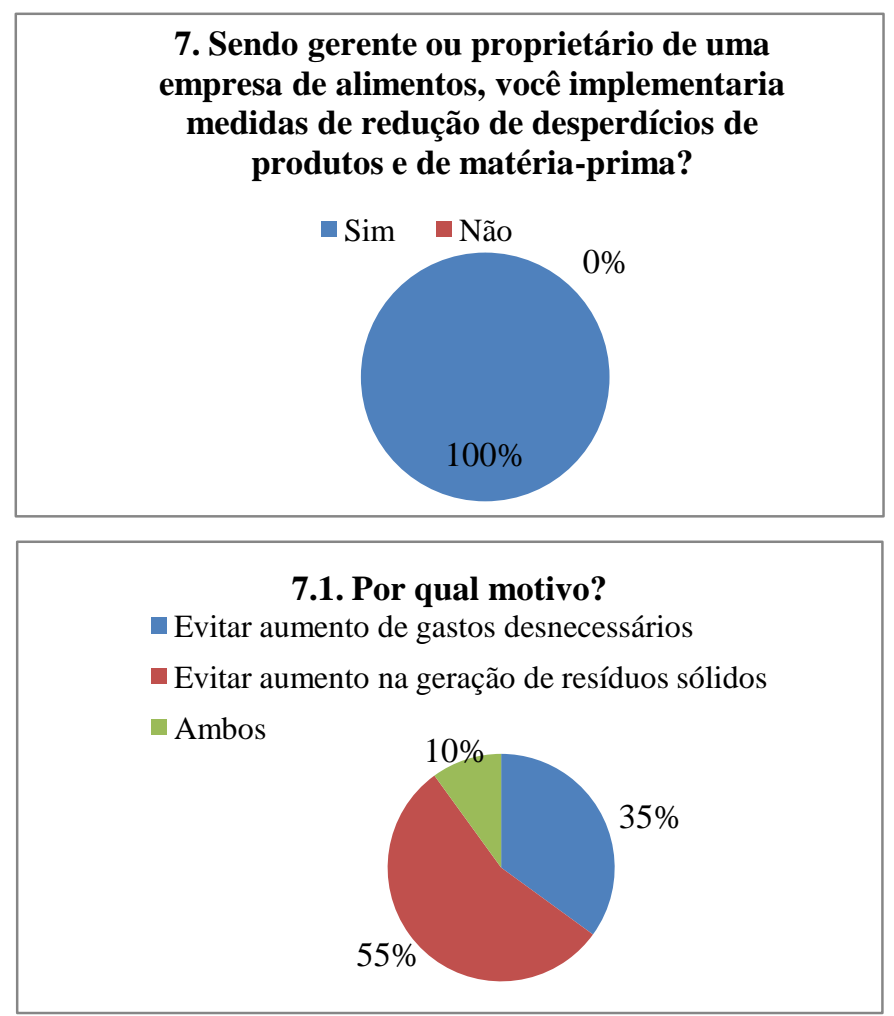

\section{Gráfico 8 - Porcentagens dos alunos que implementariam medidas de redução de desperdícios de produtos e matéria-prima e por qual motivo fariam esta implantação.}

Vê-se que predomina nesta questão o motivo ambiental, porém muitos priorizam a motivação econômica.

Considerando que o Campus Currais Novos dispõe de uma Usina de Beneficiamento de Leite que serve como laboratório de pesquisa e práticas para os alunos do curso técnico em alimentos, a questão oitava abordou acerca do tipo de efluentes uma indústria de laticínio gera. E 90\% disseram que desconhece o tipo de efluente lançado por uma unidade de processamento de leite (Gráfico 9). É importante salientar que efluentes gerados por indústrias de alimentos, principalmente laticínios, são altamente poluentes, pois se caracterizam por uma elevada carga de matéria orgânica. 
8. Você sabe que tipo de efluente uma industria de laticínio gera?

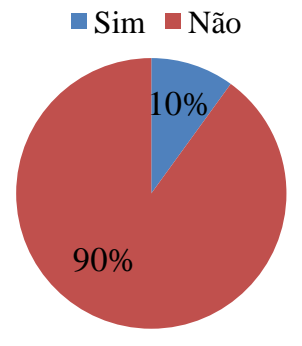

\section{Gráfico 9 - Porcentagem dos alunos que conhecem o tipo de efluentes que um laticínio gera e lança ao meio ambiente}

$\mathrm{Na}$ nona questão os alunos foram questionados se seriam de acordo com a implantação de uma empresa de alimentos altamente impactante para o meio ambiente em sua cidade. $\mathrm{O}$ gráfico abaixo mostra que $80 \%$ dos alunos responderam que não seriam de acordo e $20 \%$ responderam que sim, sendo de acordo com esta prática.

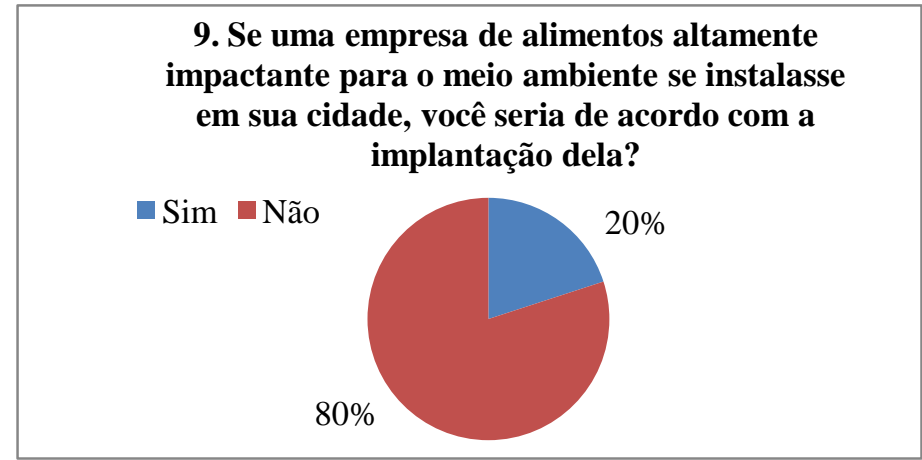

\section{Gráfico 10 - Porcentagem dos alunos que são de acordo com a implantação de} uma empresa de alimentos poluente em sua cidade.

Porém ao ler a pergunta subjetiva de "Por que" da resposta, verificou-se que houve equívocos de interpretação dada por dois alunos que responderam que "sim". O Aluno A respondeu: "Sendo impactante não seria nada bom para minha cidade". E o Aluno B respondeu: "Pois causaria danos à população".

A questão seguinte abordou sobre a Tecnologia Limpa, termo atualmente muito utilizado em empresas com preocupações ambientais e principalmente aquelas que buscam certificação ambiental. De modo que a máquina produtiva mundial tem buscado novos mercados consumidores, no qual cresce aqueles com preocupações ambientais. Apesar da importância deste termo para as empresas, $65 \%$ responderam que nunca sequer ouviram falar e 35\% já ouviram falar (Gráfico 11). 


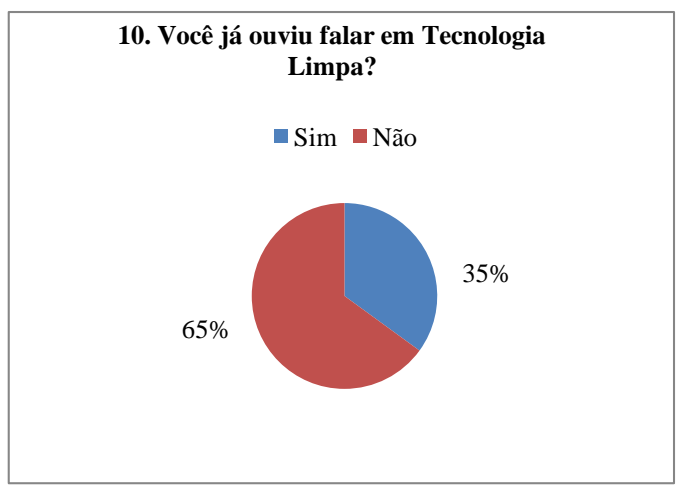

\section{Gráfico 11 - Porcentagem dos alunos que ouviram falar no termo Tecnologia Limpa.}

A décima primeira questão abordou o tema dos agrotóxicos. O gráfico 12 elucida que $70 \%$ dos estudantes afirmaram que não acham necessário o uso de agrotóxicos na produção agropecuária, $20 \%$ disseram que acha necessário e $10 \%$ não responderam a esta questão. Desses $10 \%$ percebe-se que eles optaram por não responder por não saber do que se tratava. O termo agrotóxico é muito difundido na mídia e tem sido alvos até de campanhas e estudos nos últimos anos, mesmo assim, houve alunos que não sabia a que se referia este termo.

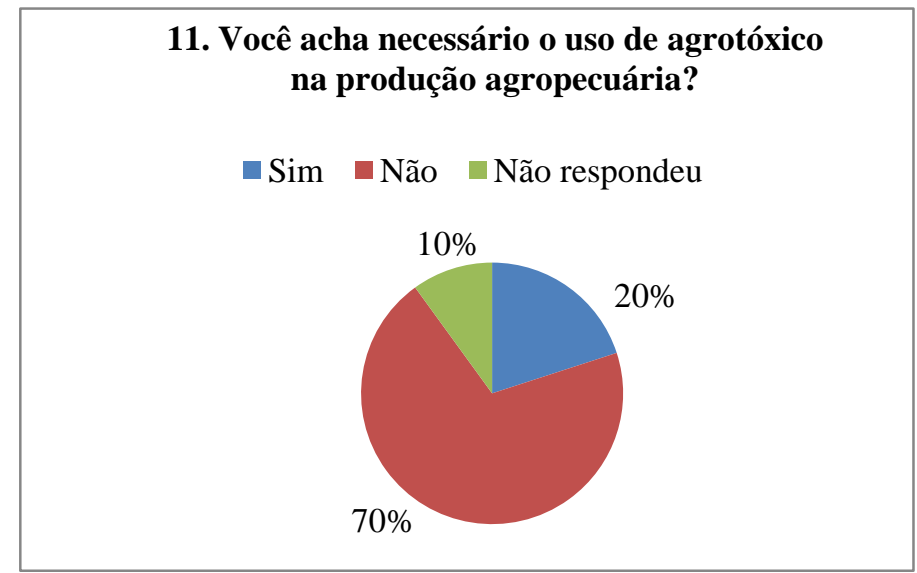

\section{Gráfico 12 - Porcentagem dos alunos que acham necessário o uso de agrotóxico na agropecuária.}

Finalmente, na última questão os estudantes expressaram sua opinião se com a formação de técnicos em alimentos, se acham aptos a dar orientações nas empresas de alimentos a fim de diminuir os impactos ambientais que elas provocam no meio ambiente. $90 \%$ dos alunos questionados afirmaram que sim, que eles são aptos nesta atividade, e 10\% afirmaram que não (Gráfico 13). 


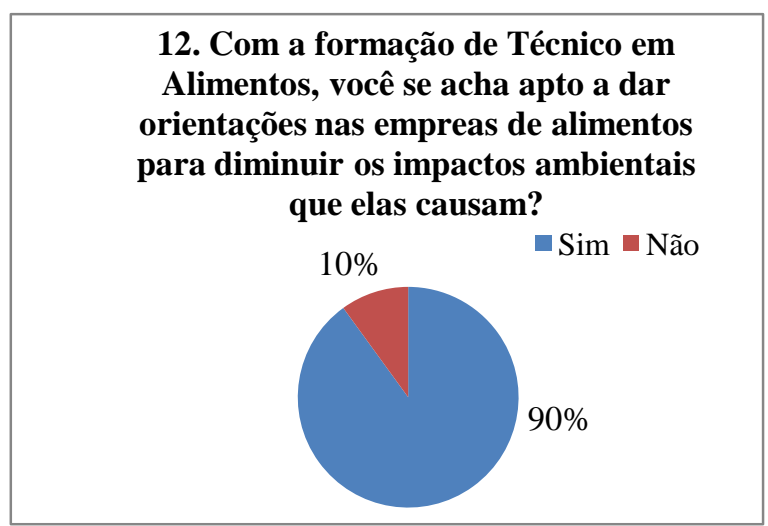

\section{Gráfico 13 - Porcentagem dos alunos que acreditam estar aptos a orientar as empresas de alimentos com sua formação de Técnico em Alimentos.}

Esta questão teve como objetivo verificar a visão que os estudantes têm sobre sua formação quanto ao meio ambiente, considerando que a formação voltada para as questões ambientais dentro das empresas de alimentos está disposta no Plano de Curso que rege a formação desses alunos.

\section{CONSIDERAÇÕES FINAIS}

A Educação Ambiental é uma forma de educação que tem como objetivos principais o desenvolvimento de uma compreensão integrada do meio ambiente em suas múltiplas e complexas relações, envolvendo aspectos ecológicos, psicológicos, legais, políticos, sociais, econômicos, científicos, culturais e éticos, e a conscientização crítica sobre a problemática ambiental e social.

Deste modo, cabe a instituições de ensino promover a educação ambiental de maneira integrada aos programas educacionais que desenvolvem, articulando as questões ambientais locais, regionais, nacionais e globais, objetivando que os estudantes atinjam um nível esperado de percepção ambiental crítica, a fim de eles buscarem as soluções para as problemáticas ambientais, a fim de compreender o mundo que o envolve.

Foi com este propósito que na matriz curricular do Curso Técnico de Nível Médio em Alimentos na Modalidade de Educação de Jovens e Adultos ofertado no Campus de Currais Novos foi inserido no último período, dentre as disciplinas da educação profissional, a disciplina de Gestão Ambiental, com o objetivo de o aluno desenvolver ações necessárias à manutenção da qualidade do meio ambiente voltadas às operações industriais com alimentos.

Diante dos resultados apresentados pode-se perceber que os alunos que estão cursando o $4^{\circ}$ período apresentaram preocupação em realizar coleta seletiva. Isso mostra que os alunos que entraram já apresentam um olhar para o meio ambiente diferenciado daqueles que concluíram, sendo mais propícios a adquirir práticas ambientalmente corretas através da educação ambiental.

Apesar de todos os alunos da turma analisada neste estudo residirem no município de Currais Novos, alguns alunos não sabiam para onde era destinado o lixo de sua residência e 
a maior parte deles afirmou que se destinava a um lixão. Este dado pode levar a dois entendimentos: os alunos consideram o aterro controlado do município um lixão ou eles desconhecem a existência do aterro. Pesquisas futuras podem elucidar este dado.

Também é preocupante o fato de alguns alunos afirmarem que no município não há corpo d'água poluído, mostrando que mesmo residindo na cidade há alunos alheios aos problemas ambientais que atingem Currais Novos, como a poluição do Rio Tororó, do Açude Público e do Açude Dourado, que não foi mencionado na pesquisa, mas é o maior açude do município e responsável por parte do abastecimento da cidade, cultivo de culturas de vazante e a atividade de piscicultura.

Apesar da água ser um recurso natural finito e alvo de grandes preocupações mundiais, houve aluno que afirmou não ser importante utilizar este recurso com parcimônia nas empresas de alimentos e houve também aluno que afirmou que o motivo pelo qual se deve economizar água seja aumentar os lucros da empresa, porém os dados apresentados pela turma cursando o $4^{\circ}$ período foi menos preocupante que o apresentado pela turma concluinte do curso de técnico em alimentos na modalidade EJA que a maioria afirmou que a motivação para a economia de água é apenas econômica, deixando de lado as questões ambientais que atingem este recurso tão importante.

O mercado consumidor está cada vez mais preocupado com as questões ambientais, por isso as empresas atualmente buscam cada vez mais soluções para as problemáticas ambientais que elas possam gerar a fim de obterem certificações internacionais, como a ISO 14.000, em busca do mercado externo. No entanto a maioria dos alunos que cursam o técnico em alimentos não possui esta preocupação ao adquirirem produtos alimentícios. Porém espera-se que o conteúdo da disciplina de Gestão Ambiental "A influência do consumidor sobre a estratégia ambiental da empresa" possa modificar as práticas desses estudantes/profissionais.

Quando os alunos foram estimulados a pensarem como gestores de empresas de alimentos mostraram um dado preocupante, pois, mesmo sendo a minoria, alguns afirmaram que implementariam medidas para reduzir os desperdícios dentro de suas empresas apenas para evitar gastos materiais, e consequentemente financeiros, desnecessários. O que aponta, mais uma vez, uma priorização da questão econômica. Poucos afirmaram que tanto o econômico quanto o ambiental são importantes dentro de uma empresa que também visa lucro, porém tem que ter a preocupação com a sustentabilidade ambiental.

Mesmo os alunos do $4^{\circ}$ período já estarem cursando disciplinas da educação profissional, como Técnica de Laboratórios, Bioquímica de Alimentos, Legislação Aplicada aos Alimentos, Controle Estatístico de Qualidade, Microbiologia e Biotecnologia de Alimentos e Máquinas, Equipamentos, Processos e Operações, a maioria deles afirmaram que desconhecem o termo Tecnologia Limpa e o tipo de efluente gerado numa indústria de laticínio e ainda há uma minoria que desconhecem o termo agrotóxico. Estes dados apontam que alunos que estão cursando a metade do curso técnico em alimentos na modalidade EJA não tiveram contato com a Usina de Beneficiamento de Leite que existe no Campus e nem com termos usados na atualidade pelas empresas de alimentos e, principalmente, pela mídia.

Diante dos dados obtidos, pode-se verificar que os alunos do PROEJA possuem um repertório de representações conhecimentos intuitivos, adquiridos pela vivência, pela 
cultura e senso comum, acerca das questões ambientais. Porém vale ressaltar que até o $4^{\circ}$ período esses alunos não cursaram a maior parte das disciplinas chamadas de técnicas, ou seja, voltada a formação de técnico em alimentos. Sendo a mais importante delas para a formação ambiental e para atingir a capacidade de monitorar os aspectos ambientais e aplicar as normas de desenvolvimento sustentável junto às empresas de alimentos, a disciplina de Gestão Ambiental, é cursada no último período do curso.

No entanto, os dados acima também mostram que as disciplinas do Curso Técnico de Nível Médio em Alimentos na Modalidade EJA estão sendo trabalhadas sem perspectiva interdisciplinar. Deste modo percebe-se que os saberes das disciplinas estão sendo abordados, porém sem o olhar ambiental integrado ao conhecimento proposto em cada disciplina. Assim o conhecimento acerca das questões ambientais está fragmentado e acumulado apenas na disciplina de Gestão Ambiental, já no final do curso, no qual os alunos terão visto grande parte do conhecimento requerido para sua formação e poderão prejudicar sua compreensão mais globalizada dos problemas ambientais gerados pelas empresas de alimentos. A percepção ambiental dos alunos deve ser estimulada desde início do curso a fim de atingir um nível esperado para que eles obtenham a formação de profissionais cidadãos a que se propõe a Instituição.

Desta forma, é preciso repensar a proposta curricular do curso técnico em Alimentos, a fim de incorporar a abordagem das questões ambientais no início do curso para assim os alunos inter-relacionar os conhecimentos da prática educacional à ambiental, além de adotar o contexto local e regional quando se tratar de aspectos ambientais, já que muitos alunos apresentaram desconhecer a realidade do município que eles estão inseridos.

Partindo desta premissa, esses alunos expressam enormes possibilidades de mudanças de alguns comportamentos, passando a se ver como veículo capaz de fazer o diferencial nestas mudanças e serem capazes de atuar em empresas de alimentos com responsabilidade ambiental.

\section{REFERENCIAS}

1. BARROS, José Deomar de Souza; SILVA, Maria de Fátima Pereira da. Educação para a Sustentabilidade Ambiental e Social em Cachoeira dos Índios - PB. Revista Brasileira de Gestão Ambiental, Mossoró, v.3, n.1, jan a dez 2009, p. 38-44.

2. BERGMANN, Melissa; PEDROZO, Catarina da Silva. Percepção Ambiental de Estudantes e Professores do Município de Giruá, RS. Revista eletrônica do Mestrado em Educação Ambiental, Rio Grande, v.19, jul adez. 2007, p. 139-156

3. _. Ministério da Educação. Programa de Integração da Educação Profissional com a Educação Básica na Modalidade de Educação de Jovens e Adultos - PROEJA. Ensino Médio. Documento Base, 2007.

4. CALDAS, Ana Luiza Rios; RODRIGUES, Maria do Socorro. Avaliação da Percepção Ambiental: estudo de caso da comunidade ribeirinha da microbacia do Rio Magu. Revista eletrônica do Mestrado em Educação Ambiental, Rio Grande, v.15, jul a dez 2005, p. 181-195.

5. CANDIANI, Giovano et al. Educação Ambiental: percepção e práticas sobre Meio Ambiente de estudantes do ensino fundamental e médio. Revista eletrônica do Mestrado em Educação Ambiental, Rio Grande, v.12, jan a jun. 2004, p. 74-89. 
6. CARVALHO, Isabel. A invenção do sujeito ecológico: sentidos e trajetórias em Educação ambiental. 2001. 349f. Tese (Doutorado em Educação), Universidade Federal do Rio Grande do Sul, Porto Alegre, 2001.

7. FREIRE, Paulo. Pedagogia do Oprimido. Rio de Janeiro: Paz e Terra, 1987.

8. HENRIQUE, Ana Lúcia Sarmento; OLIVEIRA, Leonor de Araujo Bezerra. Ações metodológicas e material didático em língua portuguesa com vistas à integração entre os conhecimentos materializados em disciplinas no Curso Técnico de Nível Médio Integrado em Controle Ambiental na Modalidade de Educação de Jovens e Adultos. Monografia (Especialização em Educação Profissional Técnica de Nível Médio Integrada ao Ensino Médio na Modalidade de Educação de Jovens e Adultos), Centro Federal de Educação Tecnológica do Rio Grande do Norte, Natal, 2007.

9. LIPAI, Eneida Maekawa; LAYRARGUES, Philippe Pomier; PEDRO, Viviane Vazzi. Educação ambiental na escola: tá na lei... . In: MELLO, Soraia Silva de; TRAJBER, Rachel (Coord.). Vamos cuidar do Brasil: conceitos e práticas em educação ambiental na escola. Brasília: Ministério da Educação, Coordenação Geral de Educação Ambiental: Ministério do Meio Ambiente, Departamento de Educação Ambiental: UNESCO, 2007, p. 23-32.

10. LIRA, Alexandre Kleber Pereira; RICARTE, Francisco Daniel Nunes. INVESTIGANDO AS CAUSAS DA EVASÃO EM CURSOS DO PROEJA NO CEFET-RN: O CASO DA UNIDADE DE CURRAIS NOVOS. Monografia (Especialização em Educação Profissional Técnica de Nível Médio Integrada ao Ensino Médio na Modalidade de Educação de Jovens e Adultos), Instituto Federal de Educação, Ciência e Tecnologia do Rio Grande do Norte, Natal, 2009.

11. MEDEIROS, Luciana de Castro. A consciência ambiental dos estudantes concluintes do PROEJA no IFRN - Campus Currais Novos. In: Colóquio Internacional de Políticas e Práticas Curriculares, 4., 2009, João Pessoa. Anais... João Pessoa: UFPB, 2009. CD-ROM.

12. MIRANDA, Daniela Janaína Pereira. Educação e Percepção Ambiental: o despertar consciente do saber ambiental para a ação do homem na natureza. Revista eletrônica do Mestrado em Educação Ambiental, Rio Grande, v.19, jul a dez 2007, p. 157164.

13. QUEIROZ, Alvamar Costa. A Práxi Ambiental na Educação Escolar. Tese (Doutorado em Educação), Universidade Federal do Rio Grande do Norte, Natal, 2002.

14. REIS, Layara; MORAIS, Márcio. Educação Ambiental no Curso Técnico em Edificações do PROEJA: percepção dos alunos quanto a influência da disciplina no seu comportamento ambiental. In: SIMPÓSIO DE PRODUTIVIDADE EM PESQUISA E ENCONTRO DE INICIAÇÃO CIENTÍFICA DO IFPI, 2., 2009, Teresina. Anais... Teresina: IFPI, 2009. Disponível em: <

15. http://www.ifpi.edu.br/eventos/iiencipro/arquivos/MEIO\%20AMBIENTE/8ad4b3e1 3676d1275f502202cb72c53c.pdf>. Acesso em: 10 mar. 2010

16. SILVA, Maria de Fátima Macêdo e; LIMA, Liz Araújo; TAVARES, Otávio Augusto de Araújo. FINANCIAMENTO NA EDUCAÇÃO BRASILEIRA: análise de recursos necessários à implantação e expansão do PROEJA. In: REIS E SILVA, Amélia Cristina; BARACHO, Maria das Graças (Orgs.). Formação de educadores para o PROEJA: intervir para integrar. Natal: CEFET-RN, 2007. 
17. SILVA, Edna Lúcia da; MENEZES, Estera Muszkat. Metodologia da pesquisa e elaboração de dissertação. 3. Ed. Florianópolis: Laboratório de Ensino a Distância da UFSC, 2001.

18. SANTOS, Marcio Quara de Carvalho; MORAES, Roseane de Paula Gomes. Análise Situacional da Percepção de Meio Ambiente por Alunos da Rede Municipal de Ensino da Cidade de Manaus, Amazonas. Revista eletrônica do Mestrado em Educação Ambiental, Rio Grande, v. 23, jul a dez 2009, p. 475-492. 